\title{
Development of Ecotourism-Based Strategy: A Case Study of Tinjomoyo Tourism Forest
}

\author{
Novie Susanto*, Denny Nurkertamanda, Heru Prastawa, and Aditya R Nugraha \\ Industrial Engineering Department, Faculty of Engineering, Diponegoro University, Semarang, \\ Indonesia
}

\begin{abstract}
Tinjomoyo Tourism Forest Area is an object or tourist destination with the concept of ecotourism-based nature conservation in the city of Semarang, Central Java Province. The number of visitors, based on the tourist destination in the last three years (2015-2017) shows that the number of tourists visiting the Tinjomoyo Tourism Forest Area are 5,949 tourists in 2015, to 13,755 tourists in 2017 . The area is inversely proportional to tourism in Semarang, including the park, Wildlife, Lele Park and Kreo Goa. To improve the visitor attention, it needs a development of potential strategy Ecotourism-based tourism objects using strengths, weaknesses, opportunities, threats (SWOT) analysis and Quantitative Strategic Planning Matrix (QSPM) analysis. This study recommends development strategies that are analysed through data processing from internal and external factors and alternative strategies that become priority strategies that can be implemented. The results of the study found 23 indicators of strength indicators and 12 weakness indicators. While for external factors there are 12 indicators that appear with details of 6 opportunity indicators and 6 threat indicators. From the indicators found, a data processing is performed using the QSPM method that produces priority strategies.
\end{abstract}

\section{Introduction}

The development of potential in the tourism industry is currently being carried out by the city/regency governments in Indonesia. The city of Semarang with its Tinjomoyo Tourism Forest (TTF) Area is currently carrying out an ecotourism-based development program, TTF Area is a natural tourist destination which is currently being carried out in more depth development efforts by the Semarang City Government and Semarang City Culture and Tourism Office. The development of tourist destinations in the tourism area of Tinjomoyo Forest included in the development of ecotourism as well as a means of bringing together conservation and community activists travel. Ecotourism is a form of a real tourism strategy to protect the environment and create income for local communities or managers based on principles that are always considered in its sustainability. Development with the ecotourism concept is carried out because in the main elements of the development concept also includes the concept of green tourism and sustainable tourism. The concept of green tourism is a concept of tourism development that applies to any activity or facility that operates in an

* Corresponding author: novie.susanto@ft.undip.ac.id 
environmentally friendly manner and orientation. The difference with ecotourism is that this concept is controlled centrally by the institution or company that regulates it, therefore the concept can focus solely on the conservation or preservation of existing flora and fauna education or both at once. Sustainable tourism is a concept of tourism development that has a way and orientation not to spend natural resources or other resources with the aim that these resources are maintained sustainably [1]. The ecotourism strategy will greatly impact economic development and conservation of natural resources [2-4]. With this, anyone who visits the Tinjomoyo Tourism Forest area will enter the environment and ecotourism activities. Tourists are required to know and adhere to the basic principles and goals of ecotourism which consist of minimizing environmental impacts, building awareness and caring for the environment and culture, providing positive experiences for visitors and managers, providing direct financial benefits for conservation, providing financial financial benefits to local communities and increasing sensitivity to the state, politics, environment and social climate [5-8].

TTF Area is a tourist attraction located in Semarang City, Central Java Province. Tourism potential in the Tinjomoyo Tourism Forest area consists of natural tourism destinations, destinations with concepts adventure and camping ground areas. Based on data on tourist destinations in the last three years, namely between 2015-2017, collected by the Disbudpar of Semarang City, the number of tourists visiting the TTF Area increased from 5,949 tourists in 2015 to 13,755 tourists in the year 2017. However, the increase in the number of tourists in the Tinjomoyo Tourism Forest area is inversely proportional to the increase in the number of tourists in three tourist attractions with other Ecotourism-based nature conservation concepts in Semarang, including Wildlife Park, Lele Park and Kreo Cave. When compared with the increase in the number of tourists in these three tourist destinations, the increase in the number of tourists in the TTF Area has the lowest increase in the number of tourists with a total of only 13,755 tourists compared to Wildlife Parks which have a total of 284,237 tourists in 2017 tourists, Goa Kreo has total tourists in 2017 which reached 174,019 tourists and Lele Park attractions which in 2017 reached 29,137 tourists [9].

From the above problems, optimal and strategy for developing the TTF Area is in sustainable line with environmental conservation programs, social, cultural and community empowerment and economic improvement based on the principles that exist in Ecotourism. This research was conducted for the design process of developing strategies on tourism potentials in the TTF Area of Semarang City and to determine and identify strategies based on existing internal and external environmental analysis. It also conducts measurement of alternative strategies that are considered to be developed from the analysis results using the methods of Strengths, Weaknesses, Opportunities, Threats (SWOT) and determining the optimal strategy of the overall strategy design using the Quantitative Strategic Planning Matrix (QSPM) method [10]. From the analysis results, identification and analysis of alternative strategies using the methods of Strengths, Weaknesses, Opportunities, Threats (SWOT) and the results of optimal strategy determination [11] using Quantitative Strategic Planning Matrix (QSPM) are considered. The next form of recommendations based on the optimal strategy or priority strategy chosen for the development of tourism potential in the Tinjomoyo Tourism Forest area that can be implemented by managers and stakeholders is performed. Recent studies related this research are discussed using different method such as development of marine tourism in Jember using Delphi [12], island tourism in Banda [13], tourism object in Semarang [14], SWOT-ANP-FANP model for prioritizing strategies in Serbia [15], SWOT analysis for tourism development strategy in Iran [16]. 


\section{Research Method}

The research design conducted in this research is observational with the support of qualitative and quantitative approaches. This research was conducted to design a development strategy based on the current conditions of the TTF Area. This research was conducted using the method of strengths, weaknesses, opportunities, threats (SWOT) and Quantitative Strategic Planning Matrix (QSPM) analysis to identify internal and external factors in the TTF Area. From the results of identification of internal and external factors, it is continued by conducting a validation process of these internal and external factors, weighting the factors that meet the requirements, identifying the alternative strategies that are formed and finally determining the priority strategies using the QSPM method.

This study consists of primary data and secondary data. Primary data was obtained by researchers through the process of identifying internal factors (strengths and weaknesses) and identification of external factors (opportunities and threats) from the TTF Area. Primary data in this study also obtained by researchers from the results of quantification of data in the questionnaire that has been weighted on the existing factors using Analytical Hierarchy Process (AHP) method [17]. Furthermore, from the results of data, the alternative strategies using Quantitative Strategic Planning Matrix (QSPM) can be performed. Secondary data was obtained by researchers from data on tourist visits for the period 2015-2017 Disbudpar Semarang City. For primary data in this study is data obtained from the quantification of data based on several questionnaires, among others:

1. Factor validation data based on the validation questionnaire of internal and external factors [11].

2. Internal and external factor weighting data through expert choice software.

3. Rating and score calculation data on internal and external factor indicators

4. Data on the calculation of Attractive Score/ AS and the value of Total Attractive Score/ TAS, alternative strategy formation data to prioritize data formation strategies through Quantitative Strategic Planning Matrix (QSPM) method.

Matrix Strengths, Weaknesses, Opportunities, Threats (SWOT) is an important matching tool that helps managers or managers to develop four types of strategies: SO Strategy (strength-opportunity), WO Strategy (weakness-opportunity), ST Strategy (threat power), and WT Strategy (weaknesses). Finding the compatibility of major external and internal factors is the hardest part in developing a matrix of Strengths, Weaknesses, Opportunities, Threats (SWOT) and requires good judgment and none of the most correct alloys.

Apart from ranking strategies to get a priority list, there is only one analytical technique in the literature designed to determine the relative attractiveness of various alternative actions. The technique is the Quantitative Strategic Planning Matrix Quantitative Strategic Planning Matrix (QSPM), which composes Phase 3 of the analytical framework of strategy formulation. This technique objectively shows which strategy is the best. QSPM uses input analysis from Phase 1 and matching results from Phase 2 analysis to objectively determine the strategies to be implemented among alternative strategies. That means External Factor Analysis Summary (EFAS) and Internal Factor Analysis Summary (IFAS) Matrix, and the Competitive Profile Matrix that composes Phase 1, plus Strengths, Weaknesses, Opportunities, Threats (SWOT) Matrix, IE Matrix, and Grand Strategy Matrix that comprise Phase 2, provide information needed to compile QSPM (Stage 3). QSPM is a tool that allows strategy makers to objectively evaluate various alternative strategies based on important external and internal success factors identified previously. As with other strategy formulation analytical tools, QSPM requires good intuitive assessment. The implementation of the strategy requires companies to set prisoner goals, make policies, motivate employees, and allocate resources, so that the formulated strategies can be implemented. The final stage in QSPM is the assessment of strategies in strategic management. Strategy evaluation and 
evaluation are the main ways to obtain this information. Three basic strategy assessment activities are a review of internal and external factors, performance measurement, and corrective steps [10].

\section{Result and Discussion}

\subsection{Internal Factors}

The results of the research process and calculations have been carried out on the internal factors are supported by in-depth discussion and study of the two managers, two stakeholders and travellers of TTF Region 3. The results get a total number of 11 strengths and 12 weaknesses. The main strength of the TTF Area is S8 about ownership of the camping ground area in this area with a score of 0.247 . In the process of operating and developing tourism objects, the TTF Area is the only nature conservation ecotourism tourism object in Semarang supported by a camping ground area that can be used as a tour with the concept of tracking and outbound adventure. The TTF Area also has several tourist attractions in terms of observing varied vegetation.

Judging from the results of the indicator score calculation Weaknesses, it shows that the highest weakness indicator score is W16 about many people who do not know Tinjomoyo Forest and what attractions are offered by Tinjomoyo Forest with a score of 0.697. The location of TTF Area is far enough from the center of Semarang City and it causes a lack of economic distribution flows. Besides, it causes less attraction of many people and by doing so, detail about the potential and tourist attractions of the TTF Area arelimited. The Semarang City Government and the Semarang City Culture and Tourism Office not focusing its development the Tinjomoyo Forest area. In addition, the management of tourism destinations in the TTF Zone itself still requires a lot of innovation related to the specific spots and identities of existing tourism to support tourism branding to be able to compete with other existing tourist destinations Semarang City such as the Central Java Grand Mosque, Lawang Sewu, Old City Area and Sam Poo Kong Temple.

\subsection{External Factors}

The results of the research process and calculations carried out on external factors supported by in-depth studies of 2 stakeholders, 2 managers and 3 tourists from the TTF Area received a total of 6 opportunities and 6 Threats. Based on the results of the calculation of the scores, the main opportunity for the TTF Area is O4. It is the condition of the development of social media that is increasingly prevalent with a score of 0.297 . This situation is a potential opportunity in the development of tourism potential in the TTF Area because today the wider community can easily access the flow of information from social media. In addition, the level of publication and branding related to tourism potential will also be easier to increase and spread more widely.

Judging from the results of calculation of score indicators threats show that the highest threat score indicator is $\mathrm{T} 4$ with a score of 0.271 which is about the lack of access conditions to the Tinjomoyo with local transport. This condition is due to the integration of transportation and infrastructure facilities related to public transportation which are still under construction and do not meet the standards. There are still many road accesses that are not yet feasible, there is no access to integration of the Rapid Trans Bus (BRT) to be able to meet the needs of route routes to and from the TTF Area. 


\subsection{IFAS and EFAS Matrix}

In the formation of the IFAS EFAS matrix it can be described through a SWOT analysis diagram that shows the position of the quadrant in determining the appropriate strategy so that it can be implemented into the process of developing tourist destinations in the TTF Area (Figure 1). The following is a calculation in the process of finding a point $(\mathrm{X}, \mathrm{Y})$ :

$$
\begin{array}{ll}
\text { Point X } & =\text { Strength }(\mathrm{S})-\text { Weakness }(\mathrm{W}) \\
\text { Total weight strength rating } & =3.282 \\
\text { Total weight rating weakness } & =4.138 \\
\text { Point X } & =-0.856 \\
\text { Point Y } & =\text { Opportunity }(\mathrm{O})-\text { Threat }(\mathrm{T}) \\
\text { Total opportunity rating weight } & =2.353 \\
\text { Total threat rating weight } & =2.077 \\
\text { Point Y } & =0.276
\end{array}
$$

IFAS EFAS matrix (Figure 1) shows that the combined strategy was selected in quadrant II, strategy Weakness-Opportunity (WO). The results of the matrix with points that are at point $(\mathrm{X}, \mathrm{Y})=(-0.856,0.276)$ in quadrant II was developed more deeply to maximize tourism potential, development of tourist attraction and market development. The Strategy for Weakness-Opportunity (WO) then be compiled according to the conditions of the TTF Zone in determining proportional alternative strategies.

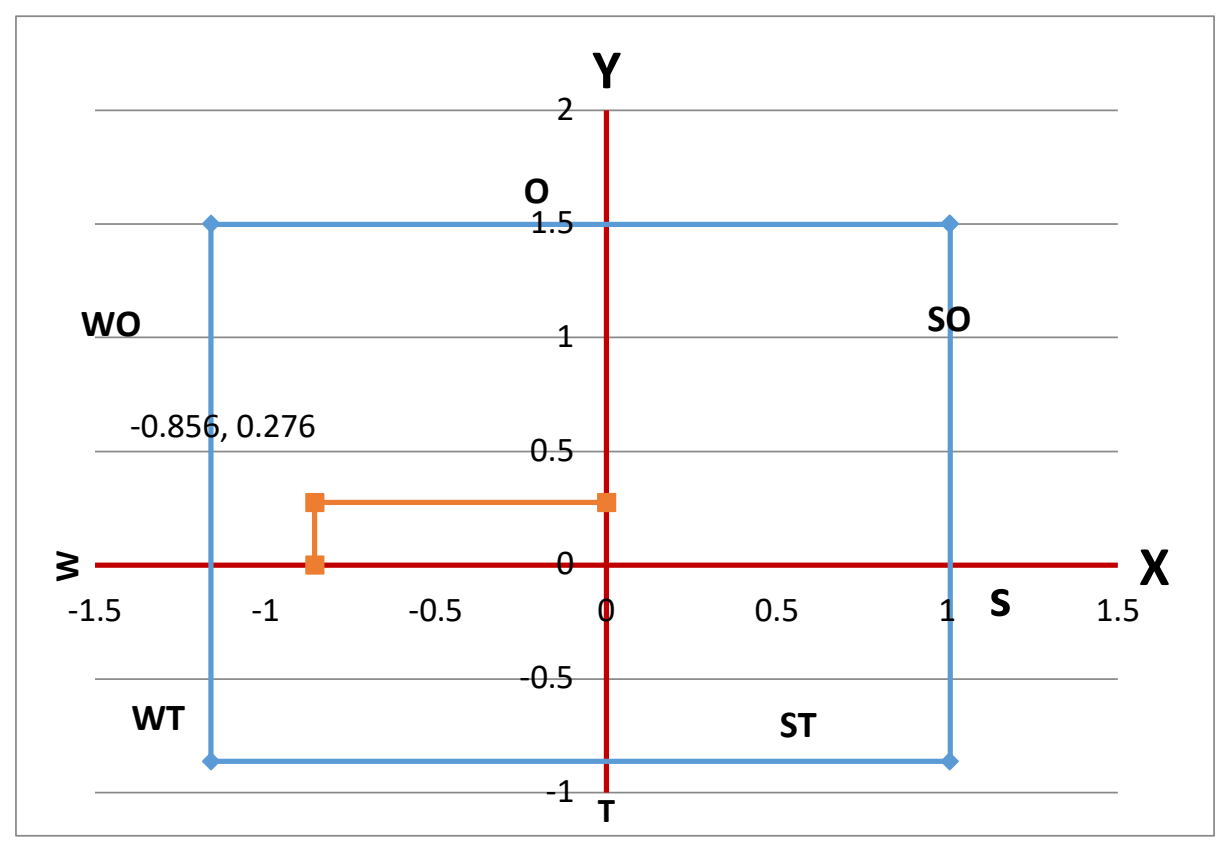

Fig. 1. IFAS Matrix and EFAS for TTF Area. 


\subsection{Alternative Strategies}

Based on the results of sharing and discussion with managers and stakeholders related, a strategy has been formed with weakness and opportunity (WO) factors. Then from these strategies several alternative strategies are formed which can be observed in table 1.

Table 1. WO Strategy with Alternative Strategies.

\begin{tabular}{cl}
\hline \multicolumn{1}{c}{ Alternative strategies } \\
\hline A1 & $\begin{array}{l}\text { Developing the tourism concept of one day night camp tracking were followed } \\
\text { by innovating publication through these activities }\end{array}$ \\
A2 & $\begin{array}{l}\text { Developing certain distinctive spots and developing disability-friendly } \\
\text { tourism concepts as well as routinely holding art and cultural performances to } \\
\text { develop tourism concepts not only focuses on nature conservation }\end{array}$ \\
A3 & $\begin{array}{l}\text { Conducting localization of Semarangan culinary area in TTF Area and making } \\
\text { innovative products such as the Tinjomoyo Forest mascot } \\
\text { Revitalizing access to the location, facilities and infrastructure and innovation } \\
\text { development of tourist attractions with concept of flowerbird park in FFT area }\end{array}$ \\
\hline
\end{tabular}

A1's alternative strategies about developing the tourism concept of one day one-night camp tracking and followed by innovating publications through these activities. Strategy A2 about developing certain distinctive spots and developing disability-friendly tourism concepts as well as routinely holding art and cultural performances to develop tourism concepts not only focuses on nature conservation. A3 Strategy about conducting localization of Semarangan culinary area in the TTF Area and making innovative products such as the Tinjomoyo Forest mascot. Strategy A4 on revitalizing access to the location, facilities and infrastructure and innovation development of tourist attractions with concept flowerbird park in forest tourism area Tinjomoyo.

\subsection{QSPM Analysis}

The results of the calculation of alternative strategies using the method Quantitative Strategic Planning Matrix (QSPM) can be seen in Table 2. The results of the QSPM matrix calculation show that TTF Area have several rating values of strategies based on each calculation of the indicator weight value and Attractive Score value (US) that has been done. The first priority strategy is revitalizing access to tourism facilities and infrastructure and innovating the development of tourist attractions with the concept of flower bird park in the TTF Area with a value of 15.264 . 
Table 2. QSPM Calculation Results.

\begin{tabular}{|c|c|c|c|c|c|c|c|c|c|c|}
\hline \multirow{2}{*}{$\mathrm{Nr}$} & \multirow{2}{*}{ Indicator } & \multirow{2}{*}{ Weight } & \multicolumn{2}{|c|}{ Strategy 1} & \multicolumn{2}{|c|}{ Strategy 2} & \multicolumn{2}{|c|}{ Strategy 3} & \multicolumn{2}{|c|}{ Strategy 4} \\
\hline & & & $\mathbf{A S}$ & TAS & $\mathbf{A S}$ & TAS & $\mathbf{A S}$ & TAS & $\mathbf{A S}$ & TAS \\
\hline 1 & S1 & 0.042 & 2 & 0.084 & 3 & 0.126 & 4 & 0.168 & 3 & 0.126 \\
\hline 2 & $\mathrm{~S} 2$ & 0.065 & 4 & 0.260 & 3 & 0.195 & 3 & 0.195 & 2 & 0.130 \\
\hline 3 & S3 & 0.098 & 4 & 0.392 & 4 & 0.392 & 3 & 0.294 & 4 & 0.392 \\
\hline 4 & S4 & 0.080 & 4 & 0.320 & 4 & 0.320 & 3 & 0.240 & 2 & 0.160 \\
\hline 5 & S5 & 0.121 & 4 & 0.484 & 4 & 0.484 & 4 & 0.484 & 4 & 0.484 \\
\hline 6 & S6 & 0.091 & 3 & 0.273 & 3 & 0.273 & 3 & 0.273 & 4 & 0.364 \\
\hline 7 & S7 & 0.104 & 4 & 0.416 & 4 & 0.416 & 4 & 0.416 & 3 & 0.312 \\
\hline 8 & S8 & 0.133 & 4 & 0.532 & 4 & 0.532 & 3 & 0.399 & 4 & 0.532 \\
\hline 9 & S9 & 0.100 & 3 & 0.300 & 3 & 0.300 & 4 & 0.400 & 3 & 0.300 \\
\hline 10 & $\mathrm{~S} 10$ & 0.087 & 2 & 0.174 & 4 & 0.348 & 3 & 0.261 & 4 & 0.348 \\
\hline 11 & $\mathrm{~S} 11$ & 0.079 & 4 & 0.316 & 3 & 0.237 & 4 & 0.316 & 3 & 0.237 \\
\hline 12 & W1 & 0.051 & 2 & 0.102 & 3 & 0.153 & 3 & 0.153 & 4 & 0.204 \\
\hline 13 & W4 & 0.027 & 3 & 0.081 & 4 & 0.108 & 3 & 0.081 & 4 & 0.108 \\
\hline 14 & W5 & 0.030 & 3 & 0.090 & 4 & 0.120 & 4 & 0.120 & 4 & 0.120 \\
\hline 15 & W7 & 0.052 & 4 & 0.208 & 4 & 0.208 & 3 & 0.156 & 4 & 0.208 \\
\hline 16 & W9 & 0.090 & 4 & 0.360 & 3 & 0.270 & 3 & 0.270 & 3 & 0.270 \\
\hline 17 & W11 & 0.084 & 4 & 0.336 & 3 & 0.252 & 4 & 0.336 & 4 & 0.336 \\
\hline 18 & W12 & 0.071 & 3 & 0.213 & 4 & 0.284 & 3 & 0.213 & 4 & 0.284 \\
\hline 19 & W13 & 0.069 & 3 & 0.207 & 4 & 0.276 & 3 & 0.207 & 3 & 0.207 \\
\hline 20 & W14 & 0.090 & 3 & 0.270 & 2 & 0.180 & 4 & 0.360 & 3 & 0.270 \\
\hline 21 & W15 & 0.410 & 3 & 1.230 & 4 & 1.640 & 4 & 1.640 & 4 & 1.640 \\
\hline 22 & W16 & 0.610 & 3 & 1.830 & 3 & 1.830 & 3 & 1.830 & 4 & 2.440 \\
\hline 23 & W17 & 0.040 & 3 & 0.120 & 3 & 0.120 & 4 & 0.160 & 3 & 0.120 \\
\hline 24 & $\mathrm{O} 1$ & 0.066 & 4 & 0.264 & 4 & 0.264 & 3 & 0.198 & 3 & 0.198 \\
\hline 25 & O3 & 0.105 & 3 & 0.315 & 4 & 0.242 & 4 & 0.420 & 4 & 0.420 \\
\hline 26 & O4 & 0.173 & 4 & 0.692 & 3 & 0.519 & 3 & 0.519 & 3 & 0.519 \\
\hline 27 & O5 & 0.201 & 2 & 0.603 & 2 & 0.401 & 4 & 0.804 & 4 & 0.804 \\
\hline 28 & O6 & 0.198 & 4 & 0.792 & 4 & 0.792 & 3 & 0.594 & 4 & 0.792 \\
\hline 29 & O7 & 0.106 & 4 & 0.212 & 3 & 0.318 & 3 & 0.318 & 4 & 0.424 \\
\hline 30 & $\mathrm{~T} 1$ & 0.071 & 4 & 0.284 & 3 & 0.213 & 3 & 0.213 & 4 & 0.284 \\
\hline 31 & $\mathrm{~T} 2$ & 0.136 & 4 & 0.544 & 4 & 0.408 & 3 & 0.408 & 3 & 0.408 \\
\hline 32 & $\mathrm{~T} 3$ & 0.143 & 4 & 0.572 & 3 & 0.286 & 2 & 0.286 & 4 & 0.572 \\
\hline 33 & $\mathrm{~T} 4$ & 0.200 & 4 & 0.800 & 3 & 0.800 & 4 & 0.800 & 3 & 0.600 \\
\hline 34 & T5 & 0.157 & 4 & 0.628 & 4 & 0.628 & 4 & 0.628 & 3 & 0.471 \\
\hline 35 & T8 & 0.060 & 3 & 0.180 & 3 & 0.180 & 3 & 0.180 & 3 & 0.180 \\
\hline \multicolumn{3}{|c|}{ TAS Total } & \multicolumn{2}{|c|}{14.484} & \multicolumn{2}{|c|}{14.373} & \multicolumn{2}{|c|}{14.340} & \multicolumn{2}{|c|}{15.264} \\
\hline \multicolumn{3}{|c|}{ Ranking } & \multicolumn{2}{|c|}{2} & \multicolumn{2}{|c|}{3} & \multicolumn{2}{|c|}{4} & \multicolumn{2}{|c|}{1} \\
\hline
\end{tabular}

\section{Conclusion}

The TTF Area is influenced by internal and external situations and conditions. In the internal conditions there are 11 power indicators that exist in the TTF Area. The strengthest indicator is ownership of the camping ground area, while the strength indicator with the lowest score is ownership land area of 57.5 hectares. As for the weakness indicators, there are 12 weaknesses in the TTF Area, with the highest weakness score indicator is about the many people who do not know about the Tinjomoyo Forest and the attractions offered in the TTF Area. The weakness indicator with the lowest score value is about the amount of resources 
owned by the TTF Area. On external conditions there are 6 opportunities indicators that exist in the TTF Zone. The opportunity indicator that has the highest score is the growing and development of social media, while the lowest score is growing tourism. The threat indicator including 6 threats that exist in the TTF Zone consist of the condition of integrated transportation access to the TTF Area as the highest score and vandalism carried out by visitors as lowest score.

From the calculation of Quantitative Strategic Planning Matrix (QSPM), it produces a top priority strategy based on the concept of Ecotourism which is the principle in this study. The main priority strategy is developing and revitalizing access to the location of the TTF Area, developing and revitalizing tourism facilities and infrastructure as well as innovating the development of tourist attractions with the concept of flower bird park in the TTF Area.

\section{References}

[1]. S. H. Zolfani, M. Sedaghat, R. Maknoon and E. K. Zavadskas. Economic ResearchEkonomska Istraživanja 28, 1 (2015).

[2]. A. Surendran and C. Sekhar The Journal of Applied Economic Research 5, 3 (2011).

[3]. T. Kiper. Role of Ecotourism in Sustainable Development. Advances in Landscape Architecture (Edited by Murat Ozyavuz). Intech Open (2013).

[4]. B. B. Boley and G. T. Green. Journal of Ecotourism. DOI: 10.1080/14724049.2015.1094080. (2015).

[5]. J. Higham. Critical issues in ecotourism: Understanding a complex tourism phenomenon. Elsevier Ltd. (2007)

[6]. A. Holden. Environment and tourism. Routledge introductions to environment series, 111 (2007).

[7]. M. Das and B. Chatterjee, B. Tourism Management Perspective, 14, (2015).

[8]. K. Wickramasinghe. Journal of Environmental Professionals Sri Lanka 1, 2 (2012).

[9]. Disbudpar Tourist Visits in Semarang City, (2017).

[10]. A. Reihanian, M. N. Zalina, E. Kahrom and T. W. H. Tourism Management Perspective, 4 (2012).

[11]. F. R. David. Strategic Management. Salemba Empat Publisher, Jakarta. (2009).

[12]. C. E. P. Nastiti and E. Umilia. Jurnal Teknik ITS. 2, 2 (2013).

[13]. K. L. O. Unga. Tesis. Universitas Hasanuddin Makasar (2011).

[14]. R. Priyanto, W. Widiartanto and S. Listyorini. Jurnal Ilmu Administrasi Bisnis S1 Undip. (2016).

[15]. S. Arsic, D. Nikolic and Z. Zivkovic. Forest Policy and Economics. 80, Juli (2017).

[16]. N. G. Raad. Journal of Tourism \& Hospitality 8, 3 (2019).

[17]. R. W. Saaty. Mathematical Modelling, 9, 3 (1987). 